\title{
PENGARUH TRAINING EMPLOYEE DAN KEMAMPUAN KERJA TERHADAP KINERJA KARYAWAN
}

\author{
Rika Indriani ${ }^{1}$ \\ Faizal Mulia ${ }^{2}$ \\ Dicky Jhoansyah ${ }^{3}$
Fakultas Ilmu Administrasi dan Humaniora Universitas Muhammadiyah
Sukabumi, Jawa Barat, Indonesia ${ }^{1,2,3}$
Email: Rikaindriani860@gmail.com¹ faizal88@ummi.ac.id ${ }^{2}$
dicky.jhoansyah@gmail.com ${ }^{3}$

\begin{abstract}
The purpose of this study is to measure the effect of employee training and work ability on employee performance. The method used in this research is descriptive and associative methods with quantitative approaches. The sampling technique in this study uses non-probability sampling using a purposive sample or sample consideration / aims, and in this case only employees of the marketing department numbering 155 employees at PT. World Innovative Telecommunication Sukabumi Branch. The data analysis technique used is multiple linear regression analysis techniques. The results of the study, using the F test the probability value sig. $0.00<0.05$ which means that together employee training $\left(X^{1}\right)$ and work ability $\left(X^{2}\right)$ have a significant influence on employee performance $(Y)$. While the $t$ test shows that employee training $\left(X^{1}\right)$ has a significant influence on employee performance $(Y)$ and work ability $\left(X^{2}\right)$ has a significant effect on employee performance $(Y)$.
\end{abstract}

Keywords: Employee Training; Work Ability; Employee Performance.

\begin{abstract}
ABSTRAK
Tujuan penelitian ini adalah untuk mengukur pengaruh training employee dan kemampuan kerja terhadap kinerja karyawan. Metode yang digunakan dalam penelitian ini adalah metode deskriptif dan metode asosiatif dengan pendekatan kuantitatif. Teknik pengambilan sampel pada penelitian ini menggunakan non probability sampling dengan menggunakan purposive sample atau sampel pertimbangan/bertujuan, dan dalam hal ini hanyalah karyawan bagian pemasaran yang berjumlah 155 karyawan yang ada pada PT. World Innovative Telecommunication Cabang Sukabumi. Teknik analisis data yang digunakan adalah teknik analisis regresi linear berganda. Hasil penelitian, menggunakan uji $\mathrm{F}$ nilai probabilitas sig. $0,00<0,05$ yang berarti bahwa bersama-sama training employee $\left(\mathrm{X}_{1}\right)$ dan kemampuan kerja $\left(\mathrm{X}_{2}\right)$ mempunyai pengaruh secara signifikan terhadap kinerja karyawan $(\mathrm{Y})$. Sedangkan pada uji t menunjukan bahwa training employee $\left(\mathrm{X}_{1}\right)$ mempunyai pengaruh secara signifikan terhadap kinerja karyawan $(\mathrm{Y})$ dan kemampuan kerja $\left(\mathrm{X}_{2}\right)$ mempunyai pengaruh secara signifikan terhadap kinerja karyawan $(\mathrm{Y})$.
\end{abstract}

Kata Kunci : Training Employee; Kemampuan Kerja; Kinerja Karyawan. 


\section{PENDAHULUAN}

Dalam rangka memenuhi kebutuhan atau keinginan konsumen, dan terus berusaha untuk meraih pangsa pasar yang ada maka perusahaan berusaha untuk mengatur dan mengelola aspek-aspek yang berhubungan dengan kinerja karyawan untuk berjalan seperti yang diharapkan oleh perusahaan. Salah satu faktor yang mempengaruhi kinerja karyawan yaitu pelatihan. Dengan adanya program pelatihan kerja akan membantu perusahaan untuk mencapai tujuan organisasi. Pada saat karyawan tersebut diterima oleh perusahaan, mereka telah memiliki keterampilan dan keahlian yang dibutuhkan. Akan tetapi mereka masih memerlukan proses penyesuaian dengan tugas-tugas yang akan diberikan dan dikerjakannya (Endayani et al., 2015). Tanpa pelatihan yang tepat karyawan tidak menerima informasi dan pengembangan keterampilan ke potensi maksimal yang digunakan untuk menyelesaikan tugas (Elnaga \& Imran, 2013).

Faktor lain yang mendukung kinerja karyawan yaitu kemampuan kerja. Kemampuan (ability) menurut (Hasibuan, 2018) menunjukkan potensi seseorang untuk melaksanakan pekerjaan, mungkin kemampuan itu dimanfaatkan atau mungkin tidak dimanfaatkan. Ketika karyawan memiliki kemampuan yang diharapkan oleh perusahaan, maka karyawan akan memiliki kualitas yang baik dan mumpuni untuk melaksanakan tugas dan kewajibannya.

PT. World Innovative Telecomunication, yang merupakan perusahaan multinasional yang bergerak dalam bidang pemasaran produk smartphone dengan nomor SIUP: 1093/1/IU/PMA/2015. Masalah yang sering terjadi di perusahaan 
smartphone ini salah satunya pada kinerja karyawan yakni kuantitas kerja yang dihasilkan oleh bagian pemasaran sangat rendah dalam hal ini hasil kerja berupa kuantitas smartphone yang terjual oleh bagian pemasaran. Hal itu sejalan dengan hasil penjajakan peneliti kepada bagian Trainer PT. World Innovative Telecomunication yang menyatakan bahwa kuantitas penjualan karyawan yang sering kali tidak stabil (naik turun), yakni kesulitan untuk mencapai target perusahaan. Permasalahan tersebut diduga disebabkan oleh salah satu dimensi yang ada pada training employee yakni metode. Dalam hal ini pemahaman peserta dalam menangkap maksud dan tujuan dari materi yang berhubungan dengan pekerjaannya serta pemahaman instuktur terhadap kebutuhan peserta pelatihan. Penyebab lainnya yaitu kemampuan fisik yang merupakan salah satu faktor yang ada dalam kemampuan kerja. Kecepatan bagian pemasaran dalam melakukan tugas - tugas yang menuntut stamina masih dinilai kurang baik. Karena untuk mencapai target dibutuhkan stamina yang cukup kuat, untuk menawarkan dan aktif berinteraksi dengan konsumen.

Menurut (Hazrati-Viari et al., 2012), pelatihan kerja (training employee) didefinisikan sebagai kegiatan yang terorganisir yang mempunyai tujuan untuk meningkatkan kinerja karyawan. Selain itu, manfaat lainnya akan mengurangi penggunaan biaya pada pekerjaannya, dan akan berpengaruh secara langsung pada peningkatan produktivitas (Bangun, 2012). Menurut (Ramya, 2016) Program pelatihan adalah stimulan yang dibutuhkan pekerja untuk meningkatkan kinerja dan kemampuan mereka, yang akibatnya meningkatkan produktivitas organisasi. Ada beberapa dimensi dalam pelatihan seperti dijelaskan oleh (Dessler, 2015) yaitu (1) 
instruktur; (2) peserta; (3) materi; (4) metode; (5) tujuan. Maka penelitian ini menggunakan lima dimensi pelatihan kerja (training employee) menurtu (Dessler, 2015) yaitu : (1) instruktur; (2) peserta; (3) materi; (4) metode; (5) tujuan.

Penelitian terdahulu mengenai pelatihan kerja (training employee) dimana penelitian terdahulu (Trawardani et al., 2015; Endayani et al., 2015; Rudhaliawan et al., 2013; Imran, 2013; Utami, 2016; Angela, 2014; Ramya, 2016) menyatakan bahwa pelatihan kerja (training employee) berpengaruh positif dan signifikan terhadap kinerja karyawan. Sedangkan penelitian yang dilakukan oleh (Hok, 2014) mengungkapkan bahwa pelatihan kerja tidak berpengaruh nyata terhadap kinerja karyawan. Hal ini karena proses pelatihan mulai dari perencanaan kebutuhan pelatihan, perancangan program pelatihan, pelaksanaan pelatihan, dan penilaian pelatihan belum dilaksanakan secara baik.

$\mathrm{H}_{1} \quad$ : Terdapat pengaruh training employee terhadap kinerja karyawan pada PT. World Innovative Telecomunication Cabang Sukabumi.

Kemampuan kerja didefinisikan sebagai kemampuan merujuk kesatu kapasitas individu untuk mengerjakan berbagai tugas dalam suatu pekerjaan (Robbins et al., 2017). Peningkatan kemampuan karyawan dapat diperoleh melalui program pelatihan yang pernah diikuti serta pengalaman kerja yang dimiliki (Endayani et al., 2015). Beberapa dimensi atau kriteria yang perlu mendapat perhatian sebagai indikator dalam pengukuran kemampuan kerja menurut (Robbins et al., 2017), antara lain (1) kemampuan intelektual, yaitu kemampuan yang dibutuhkan untuk melakukan berbagai aktivitas mental, berfikir, menalar, dan memecahkan masalah dan (2) kemampuan fisik, adalah kemampuan melakukan 
tugas - tugas yang menuntut stamina, keterampilan, dan karakteristik serupa. Maka peneliti menggunakan dimensi menurut (Robbins et al., 2017), yaitu (1) kemampuan intelektual; (2) kemampuan fisik.

Penelitian terdahulu mengenai kemampuan kerja yang dilakukan oleh (Trawardani, et al., 2015; Endayani, et al., 2015; Utami, 2016), menyatakan bahwa kemampuan kerja berpengaruh positif dan signifikan terhadap kinerja karyawan.

$\mathrm{H}_{2}$ : Terdapat pengaruh kemampuan kerja terhadap kinerja karyawan pada PT. World Innovative Telecomunication Cabang Sukabumi.

Kinerja adalah hasil kerja secara kualitas dan kuantitas pekerjaan yang dilakukan oleh karyawan sesuai dengan tugas yang dipercayakan kepadanya. (Mangkunegara, 2016) (Endayani et al., 2015). Menurut (Sutrisno, 2017) mengungkapkan beberapa dimensi yang membutuhkan perhatian sebagai indikator kinerja, antara lain (1) hasil kerja; (2) pengetahuan pekerjaan; (3) inisiatif; (4) kecekatan mental; (5) sikap; (6) disiplin waktu dan absensi. Maka peneliti menggunakan enam dimensi kinerja karyawan menurut (Sutrisno, 2017) yaitu (1) hasil kerja; (2) pengetahuan pekerjaan; (3) inisiatif; (4) kecekatan mental; (5) sikap; (6) disiplin waktu dan absensi.

Penelitian terdahulu mengenai kinerja karyawan yang dilakukan oleh Utami (2016), menyatakan bahwa, training employee dan kemampuan kerja berpengaruh positif dan signifikan terhadap kinerja karyawan. 
$\mathrm{H}_{3} \quad$ : Terdapat pengaruh training employee dan kemampuan kerja terhadap kinerja karyawan pada PT. World Innovative Telecomunication Cabang Sukabumi.

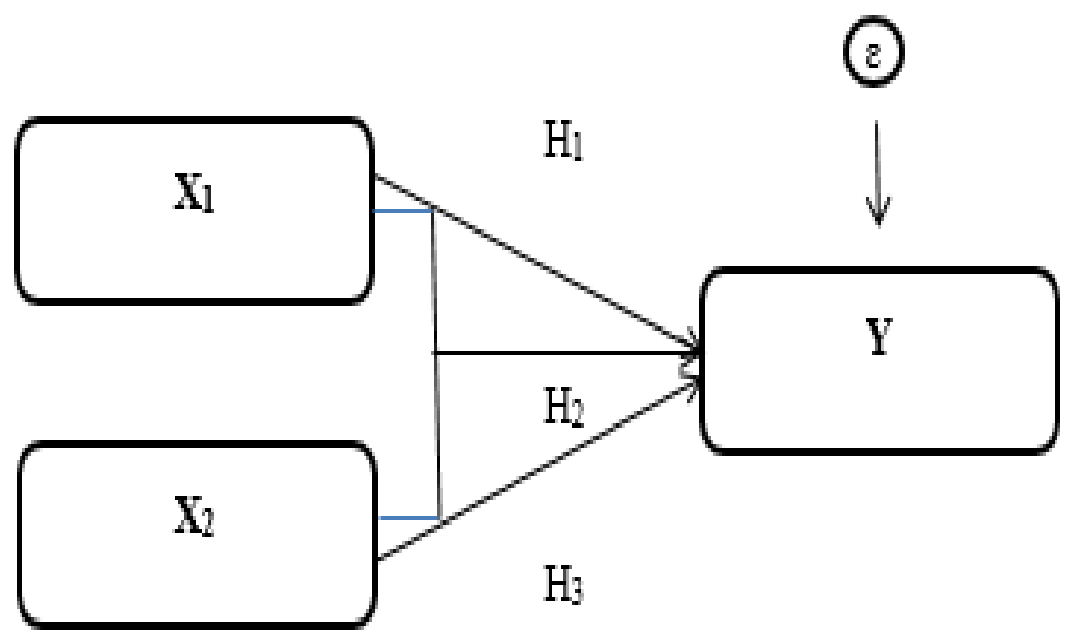

Sumber: Data diolah oleh peneliti 2020

Gambar 1.

\section{Model Penelitian}

Keterangan :

Variabel $\mathrm{X}_{1} \quad=$ training employee

Variabel $\mathrm{X}_{2} \quad=$ kemampuan kerja

Variabel Y = kinerja karyawan

$\varepsilon \quad=$ faktor lain dalam penelitian

Dengan mengamati gejala atau fenomena yang terjadi, menunjukan bahwa belum optimalnya pelaksanaan training employee dan kemampuan kerja karyawan sehingga diduga menyebabkan kinerja yang kurang baik. Oleh karena itu peneliti menganggap perlu untuk mengkaji lebih dalam mengenai training employee dan 
kemampuan kerja terhadap kinerja karyawan pada PT. World Innovative Telecomunication cabang Sukabumi, sehingga mendorong peneliti memilih judul "Pengaruh Training Employee dan Kemampuan Kerja terhadap Kinerja Karyawan".

\section{METODE PENELITIAN}

Penelitian ini dilaksanakan pada PT. World Innovative Telecomunication Cabang Sukabumi. Metode yang digunakan dalam penelitian ini adalah metode deskriptif dan metode asosiatif dengan pendekatan kuantitatif. Teknik pengambilan sampel pada penelitian ini menggunakan non probability sampling dengan menggunakan purposive sample atau sampel pertimbangan/bertujuan, dan dalam hal ini hanyalah karyawan bagian pemasaran yang berjumlah 155 karyawan yang ada pada PT. World Innovative Telecommunication Cabang Sukabumi. Teknik pengambilan data yang penelti gunakan dalam penelitian ini yaitu observasi, wawancara, kuesioner, studi kepustakaan, dan dokumentasi. Teknik analisis data yang digunakan adalah teknik analisis regresi linear berganda, termasuk uji koefisien determinasi, koefisien kolerasi ganda, uji secara simultan (uji F) dan uji secara parsial (uji T).

\section{HASIL DAN PEMBAHASAN}

Analisis regresi linear berganda digunakan oleh peneliti, untuk meneliti suatu pengaruh dari beberapa variabel yang berkolerasi dengan variabel yang lain yang akan diuji. Dari hasil regresi linear berganda ini dapat dilihat pada Tabel 1. 
Tabel 1.

Hasil Uji Regresi Linear Berganda

\begin{tabular}{|c|c|c|c|c|c|c|}
\hline \multicolumn{7}{|c|}{ Coefficients $^{a}$} \\
\hline & & & & Standardize & & \\
\hline & & $\begin{array}{r}\text { Unst: } \\
\text { Co } \\
\end{array}$ & $\begin{array}{l}\text { dardized } \\
\text { ficients }\end{array}$ & $\begin{array}{c}\text { d } \\
\text { Coefficients } \\
\end{array}$ & & \\
\hline \multicolumn{2}{|c|}{ Model } & B & Std. Error & Beta & $\mathbf{t}$ & Sig. \\
\hline \multirow[t]{5}{*}{1} & (Constant) & 3,083 & 1,256 & & 2,454 &, 015 \\
\hline & Training &, 370 & ,060 & ,359 & 6,161 & ,000 \\
\hline & Employee & & & & & \\
\hline & Kemampuan & ,734 & ,072 & ,599 & 10,264 & ,000 \\
\hline & Kerja & & & & & \\
\hline
\end{tabular}

a. Dependent Variable: Kinerja Karyawan

Sumber : Data Primer (Kuesioner), 2020

Dari hasil uji regresi linear berganda, maka dapat diperoleh persamaan:

$Y=3,083+0,370 X_{1}+0,734 X_{2}$

Tabel 2.

\section{Hasil Koefisien Determinasi}

\begin{tabular}{ccccc}
\hline \multicolumn{5}{c}{ Model Summary } \\
\hline Model & $\mathbf{R}$ & Square & $\begin{array}{c}\text { Adjusted R } \\
\text { Square }\end{array}$ & $\begin{array}{c}\text { Std. Error } \\
\text { of the } \\
\text { Estimate }\end{array}$ \\
\hline 1 &, $922^{\mathrm{a}}$ &, 849 &, 847 & 2,60337 \\
\hline
\end{tabular}

a. Predictors: (Constant), Kemampuan Kerja, Training Employee

Sumber : Data Primer (Kuesioner), 2020

Hasil Tabel 2 menunjukan besarnya nilai adjusted $\mathrm{R}^{2}$ yaitu 0,849 ; maka hal ini menunjukan $84,9 \%$ variabel kinerja karyawan dapat dijelaskan oleh kedua variabel independen yaitu training employee dan kemampuan kerja. Sementara $15,1 \%$ berasal dari faktor yang tidak diteliti dalam penelitian. 
Tabel 3.

Hasil Koefisien Kolerasi Ganda

\begin{tabular}{lcrrr}
\hline \multicolumn{5}{c}{ Model Summary } \\
\hline Model & R & R Square & $\begin{array}{c}\text { Adjusted R } \\
\text { Square }\end{array}$ & $\begin{array}{c}\text { Std. Error of } \\
\text { the Estimate }\end{array}$ \\
\hline 1 &, $922^{\text {a }}$ &, 849 &, 847 & 2,60337 \\
\hline a. Predictors: (Constant), Kemampuan Kerja, Training Employee
\end{tabular}

Sumber : Data Primer (Kuesioner), 2020

Hasil Tabel 3 menunjukan bahwa hasil yang diperoleh angka $\mathrm{R}$ sebesar 0,992 hasil ini berada pada kategori $0,80-1,000$. Hal ini menunjukan bahwa adanya hubungan yang sangat kuat antara training employee dan kemampuan kerja dengan kinerja karyawan.

Tabel 4

Hasil Uji F

\begin{tabular}{|c|c|c|c|c|c|c|}
\hline \multicolumn{7}{|c|}{ ANOVA $^{a}$} \\
\hline \multicolumn{2}{|c|}{ Model } & $\begin{array}{c}\text { Sum of } \\
\text { Squares }\end{array}$ & df & $\begin{array}{c}\text { Mean } \\
\text { Square }\end{array}$ & $\mathbf{F}$ & Sig. \\
\hline \multirow[t]{3}{*}{1} & Regression & 5808,553 & 2 & 2904,276 & 428,516 &, $000^{\mathrm{b}}$ \\
\hline & Residual & 1030,183 & 152 & 6,778 & & \\
\hline & Total & 6838,735 & 154 & & & \\
\hline
\end{tabular}

a. Dependent Variable: Kinerja Karyawan

b. Predictors: (Constant), Kemampuan Kerja, Training Employee

Sumber : Data Primer (Kuesioner), 2020

Hasil Tabel 4 menunjukan bahwa hasil uji $\mathrm{F}$ yang telah dilakukan dapat diperoleh nilai sig. $0,000<0,05$; nilai $F_{\text {hitung }} 428,516>F_{\text {Tabel }} 3,06$. Artinya bahwa training employee dan kemampuan kerja secara bersama-sama (simultan) berpengaruh terhadap kinerja karyawan. Hal ini dapat disimpulkan bahwa 
karyawan akan menghasilkan kinerja yang baik apabila training employee mendapatkan perhatian yang besar.

Dengan adanya pelatihan diharapkan karyawan akan bekerja secara efektif dan efisien terutama untuk menghadapi perubahan-perubahan yang terjadi seperti perubahan teknologi, perubahan metode kerja, menuntut pula perubahan sikap, tingkah laku, keterampilan dan pengetahuan. Selain itu karyawan yang memiliki kemampuan dan keterampilan pun akan mendukung hasil kerja karyawan itu sendiri. Hasil penelitian ini sejalan dengan penelitian yang dilakukan oleh Utami (2016), menyatakan bahwa, "training employee dan kemampuan kerja berpengaruh positif dan signifikan terhadap kinerja karyawan.”

Tabel 5.

\section{Hasil Uji T}

\begin{tabular}{|c|c|c|c|c|c|c|}
\hline \multicolumn{7}{|c|}{ Coefficients $^{\mathrm{a}}$} \\
\hline & & \multicolumn{2}{|c|}{$\begin{array}{c}\text { Unstandardized } \\
\text { Coefficients }\end{array}$} & \multirow{2}{*}{$\begin{array}{c}\text { Standardized } \\
\text { Coefficients }\end{array}$} & \multirow[b]{2}{*}{$\mathbf{t}$} & \multirow[b]{2}{*}{ Sig } \\
\hline \multicolumn{2}{|l|}{ Model } & B & Std. Error & & & \\
\hline \multirow[t]{5}{*}{1} & (Constant) & 3,083 & 1,256 & & 2,454 &, 015 \\
\hline & Training &, 370 &, 060 &, 359 & 6,161 & ,000 \\
\hline & Employee & & & & & \\
\hline & Kemampuan &, 734 &, 072 & ,599 & 10,26 & 000 \\
\hline & Kerja & & & & 4 & \\
\hline
\end{tabular}

a. Dependent Variable: Kinerja Karyawan

Sumber : Data Primer (Kuesioner), 2020

Hasil Tabel 5 menunjukan bahwa hasil uji $\mathrm{T}$ yang telah dilakukan pada variabel training employee menghasilkan nilai dengan sig. $0,000<0,05$; nilai $\mathrm{T}_{\text {hitung }}$ $6,166>\mathrm{T}_{\text {Tabel }} 1,97569$. Artinya bahwa training employee secara parsial berpengaruh 
positif dan signifikan terhadap kinerja karyawan, Hal ini menunjukan bahwa karyawan memberikan tanggapan baik pada training employee dalam hal instruktur, peserta, materi, metode, dan tujuan sehingga mampu memberikan kinerja yang baik pada PT. World Innovative Telecomunication Cabang Sukabumi. Hasil penelitian ini sejalan dengan penelitian yang dilakukan oleh Trawardani, et al., (2015), Endayani, et al., (2015), Rudhaliawan et al., (2013), Imran (2013), Utami (2016), Angela (2014), dan Ramya (2016), menyatakan bahwa, "pelatihan kerja berpengaruh positif dan signifikan terhadap kinerja karyawan."

Selanjutnya variabel kemampuan kerja menghasilkan nilai dengan sig. $0,000<0,05$; nilai $\mathrm{T}_{\text {hitung }} 10,264>\mathrm{T}_{\text {Tabel }} 1,97569$. Artinya bahwa kemampuan kerja secara parsial berpengaruh positif dan signifikan terhadap kinerja karyawan. Dari hasil yang diperoleh dapat disimpulkan bahwa Kemampuan Kerja berpengaruh signifikan terhadap Kinerja Karyawan. Hal ini menunjukan bahwa karyawan memberikan tanggapan baik pada kemampuan kerja dalam hal kemampuan intelektual yakni kemampuan yang dibutuhkan untuk melakukan berbagai aktivitas mental, berfikir, menalar, dan memecahkan masalah dan kemampuan fisik yakni kemampuan melakukan tugas - tugas yang menuntut stamina, keterampilan, dan karakteristik serupa sehingga mampu memberikan kinerja yang baik pada PT. World Innovative Telecomunication Cabang Sukabumi. Hasil penelitian ini sejalan dengan penelitian yang dilakukan oleh Trawardani, et al., (2015), Endayani, et al., (2015), Utami (2016), menyatakan bahwa, "kemampuan kerja berpengaruh positif dan signifikan terhadap kinerja karyawan." 


\section{SIMPULAN DAN SARAN}

Berdasarkan dari hasil pengujian uji $\mathrm{T}$, training employee berpengaruh positif dan signifikan terhadap kinerja karyawan, dan kemampuan kerja secara parsial berpengaruh positif dan signifikan terhadap kinerja karyawan. Dan secara simultan pada variabel training employee dan kemampuan kerja secara bersamasama (simultan) berpengaruh positif dan signifikan terhadap kinerja karyawan pada PT. World Innovative Telecomunication Cabang Sukabumi. Secara parsial,

Berdasarkan hasil penelitian yang diperoleh dari analisis data, maka saran yang dapat diberikan oleh peneliti kepada PT. World Innovative Telecomunication Cabang Sukabumi adalah :(1) Disarankan kepada perusahaan untuk mengkemas pelatihan kerja lebih menarik dan mudah dipahami supaya peserta dapat menangkap maksud dan tujuan dari materi yang berhubungan dengan pekerjaannya. (2) Perusahaan sebaiknya melatih kemampuan kerja karyawan dari segi fisik seperti membagikan brosur kepada orang yang lalu lalang didepan toko, mempromosikan produk smartphone menggunakan microphone guna menjangkau lebih luas. Hal tersebut bertujuan agar karyawan dapat melakukan tugas - tugas yang menuntut stamina yang cukup kuat sehingga dapat lebih maksimal dalam menawarkan produk dan aktif berinteraksi dengan konsumen. (3) Penelitian ini diharapkan dapat dijadikan sebagai sarana informasi sehingga dalam penelitian selanjutnya dapat memperbaiki keterbatasan yang ada dalam penelitian ini dengan melakukan penelitian pada sektor lain dan memperluas variabel mengenai training employee, kemampuan kerja, dan kinerja karyawan agar dapat mengembangkan 
penelitian dengan menggunakan variabel lain, sehingga dapat mendukung dalam penelitian selanjutnya.

\section{REFERENSI}

Angela, G. (2014). Effects of Training on Employee Performance: A Case Study Of United Nations Support Office For The African Union Mission in Somali. Retrieved from http://erepo.usiu.ac.ke/11732/71

Bangun, W. (2012). Manajemen Sumber Daya Manusia. Jakarta: Erlangga.

Dessler, G. (2015). Manajemen Sumber Daya Manusia. Jakarta: Salemba Empat.

Elnaga, D. A., \& Imran, A. (2013). The Effect Of Training On Employee Performance. European Journal of Business and Management|Vol. 5 No. 4 2013|, 5(4), 137-147.

Endayani, F., Hamid, D., \& Djudi, M. (2015). Pengaruh Pelatihan Kerja Terhadap Kemampuan Kerja dan Kinerja Karyawan (Studi Pada PT. BPRS Bumi Rinjani Kepanjen). Jurnal Administrasi Bisnis (JAB)|Vol. 25 No. 1 Agustus 2015|, 25(1), 1-7.

Hasibuan. (2018). Manajemen Sumber Daya Manusia. Jakarta: PT.Bumi Aksara.

Hazrati, Viari, A., Rad, A. T., \& Torabi, S. S. (2012). The Effect Of Personality Traits On Academic Performance: The Mediating Role Of Academic Motivation. Procedia - Social and Behavioral Sciences|Vol. 32, 2012|, 25(1), 367-371.

Hok, T. T. (2014). Pengaruh Pelatihan dan Motivasi terhadap Kinerja Karyawan. Sosiohumaniora Journal of Social Sciences and Humanities|Vol. 16 No.2 Juli 2014|, 16(2), 215-221.

Mangkunegara, A. A. A. P. (2016). Evaluasi Kerja. Bandung: PT. Refika Aditama.

Ramya. (2016). The Effect of Traning Employee on Employee Performance. International Journal of Scientific Research and Modern Education, International Journal of Scientific Research and Modern Education (IJSRME) | Vol. 1 No. 1, 2016|, 1(1), 697-706.

Rudhaliawan. (2013). Pengaruh Pelatihan Terhadap Kemampuan Kerja dan Kinerja Karyawan. Jurnal Administrasi Bisnis (JAB) Universitas Brawijaya 
|Vol. 4 No. 2 , 2013|, 4(2), 1-10.

Robbins, S. P., Judge, T. A., \& Campbell, T. T. (2017). Organizational Behavior: Second Edition. In Pearson.

Sutrisno, Edy. (2017). Manajemen Sumber Daya Manusia, Edisi Ke-9, Jakarta: Kencana.

Trawardani, I. B. (2015). Pengaruh Pelatihan Kerja Terhadap Kemampuan Kerja yang Berdampak Pada Kinerja Karyawan. ( Studi Pada Karyawan PT Bank Rakyat Indonesia ( Pesero ) Tbk Cabang Lumajang ). Jurnal Administrasi Bisnis (JAB) Universitas Brawijaya |Vol. 29 No. 1 , 2015| 29(1),51-58.

Utami, D. (2016). Pengaruh Pelatihan, Kemampuan Kerja Dan Pengembangan Karir Terhadap Kinerja Pegawai Pada Dinas Pendidikan Pemuda Dan Olahraga Kabupaten Kudus. Retrieved from https://onesearch.id/Record/IOS3090.6027 